\title{
Pharmacologic Agents That Promote Airway Clearance in Hospitalized Subjects: A Systematic Review
}

\author{
Nila A Sathe MA MLIS, Shanthi Krishnaswami MBBS MPH, Jeff Andrews MD, \\ Cathy Ficzere PharmD BCPS, and Melissa L McPheeters PhD MPH
}

\author{
Introduction \\ Methods \\ Literature Search Strategy \\ Inclusion and Exclusion Criteria \\ Study Selection \\ Data Extraction and Synthesis \\ Quality (Risk of Bias) Assessment of Individual Studies \\ Results \\ Summary of Results by Agent \\ Discussion \\ Summary of Results by Outcome \\ Methodological Considerations and Limitations \\ Future Research \\ Conclusions
}

\begin{abstract}
Pharmacologic agents to promote mucus clearance may reduce the sequelae of obstructive secretions. We systematically reviewed comparative studies of pharmacologic agents for mucus clearance in hospitalized or postoperative subjects without cystic fibrosis and over 12 months of age. We searched MEDLINE and other databases from January 1970 to July 2014 to identify relevant literature. Two reviewers independently assessed each study against predetermined inclusion/exclusion criteria. Two reviewers also independently extracted data regarding subject and intervention characteristics and outcomes and assigned overall quality ratings. The 9 studies meeting review criteria included 5 randomized controlled trials, 3 crossover randomized controlled trials, and one retrospective cohort study. Studies were small and together included a total of 379 subjects (mean of 42 subjects per study). $\mathrm{N}$-acetylcysteine, heparin plus $\mathrm{N}$-acetylcysteine, albuterol, ipratropium bromide, and saline were assessed. Studies reported no benefit of studied agents on expectoration, pulmonary function, and atelectasis and little effect on changes in sputum volume, weight, or viscosity. Adverse effects of agents were not consistently reported. Nausea was reported in 2 studies of $\mathbf{N}$-acetylcysteine (one paper reported 2 experiments and did not clearly identify in which experiment adverse effects occurred), 3 studies reported that there were no adverse events, and 3 studies did not address adverse effects at all. Further research with clearly characterized populations and interventions is needed to understand the potential benefits and adverse effects of mucoactive agents. Key words: airway clearance; mucus clearance; mucoactive agents; drug therapy. [Respir Care 2015;60(7):1061-1070. (C) 2015 Daedalus Enterprises]
\end{abstract}

\section{Introduction}

Mucus hypersecretion can be pathologic in individuals with severe respiratory disease or impaired cough. Al-

Ms Sathe and Drs Krishnaswami, Andrews, and McPheeters are affiliated with the Vanderbilt Evidence-based Practice Center, Institute for Medicine and Public Health, and Ms Sathe and Dr McPheeters are also affil- though airway cilia clear mucus continually in healthy individuals, in the presence of inflammation or infection, mucus production increases, ciliary function may become

iated with the Department of Health Policy, Vanderbilt University Medical Center, Nashville, Tennessee. Dr Ficzere is affiliated with the Christy Houston Foundation Drug Information Center, Belmont University College of Pharmacy, Nashville, Tennessee. 
impaired, and the biophysical properties of sputum may change. ${ }^{1,2}$ Mucus hypersecretion is associated with declines in pulmonary function and quality of life, excess cough, discomfort, and exacerbation of conditions such as COPD. ${ }^{3,4}$ Mucoactive agents may increase sputum expectoration or decrease hypersecretion of mucus. ${ }^{1,5,6}$ Mucolytic agents such as $\mathrm{N}$-acetylcysteine alter disulfide bonds that comprise mucus proteins and may decrease mucus viscosity. ${ }^{1,5,6}$ Other mucolytics such as dornase alfa break down deoxyribonucleic acid polymers or networks of actin filaments that develop in purulent secretions. Expectorants may promote loosening of airway secretions. Agents such as saline may rehydrate mucus and promote cough. ${ }^{7} \mathrm{Mu}-$ coregulatory agents target chronic hypersecretion by goblet cells and submucosal glands. ${ }^{1,5,6}$ Agents include corticosteroids, macrolide antibiotics, and anticholinergics such as ipratropium bromide. Mucokinetic agents such as bronchodilators promote clearance by increasing action of the cilia and may facilitate mucus transportability. ${ }^{1,2,7}$ Surfactants may also reduce mucus adhesiveness and increase transportability. ${ }^{6}$

The goal of this project was to systematically review comparative studies of pharmacologic agents that respiratory therapists and other health professionals can employ to achieve mucus clearance in hospitalized or postoperative patients over the age of 12 months. The American Association for Respiratory Care (AARC) commissioned the review, and AARC committee members participated in the review process. As a collaborative effort, the AARC team and the Vanderbilt Evidence-based Practice Center (EPC) developed the key questions and inclusion and exclusion criteria and engaged in identification and review of abstracts. AARC members involved in the work were paired with EPC staff to maintain rigor and protect against bias. This team previously reviewed the benefits and harmful effects of nonpharmacologic airway clearance techniques in hospitalized subjects. ${ }^{8}$

Supplementary material related to this paper is available at http:// www.rcjournal.com.

This study was supported by the American Association for Respiratory Care. The authors have disclosed no conflicts of interest.

Correspondence: Melissa L McPheeters PhD MPH, Vanderbilt Evidencebased Practice Center, Department of Health Policy, Vanderbilt University Medical Center, 6th Floor, 2525 West End Avenue, Nashville, TN 37203. E-mail: melissa.mcpheeters@vanderbilt.edu.

DOI: $10.4187 /$ respcare. 04086

\section{Methods}

\section{Literature Search Strategy}

Detailed methods for the review can be found in the full report at http://www.rcjournal.com. Briefly, we used the search strategies provided in the online appendix to retrieve relevant research on pharmacologic agents that promote mucus clearance. Our primary literature search employed the MEDLINE (via the PubMed interface) and Embase databases. Our search strategies used a combination of subject heading terms appropriate for each database and key words relevant to airway clearance and pharmacologic agents (eg, sputum clearance, albuterol, anticholinergics). We limited searches to literature published in English since 1970 to ensure that older agents would be represented. Our searches were last conducted in July 2014. We imported all citations into an electronic database and into the DistillerSR program (Evidence Partners, Ottawa, Ontario, Canada) for screening. We also manually searched the reference lists of included studies and of recent narrative and systematic reviews and meta-analyses addressing airway clearance in adults to locate citations of potential relevance.

\section{Inclusion and Exclusion Criteria}

Studies needed to include individuals over $1 \mathrm{y}$ of age without cystic fibrosis who were receiving pharmacologic agents to promote airway clearance and who were either hospitalized (but not postoperative) or postoperative, had neuromuscular disease or respiratory muscle weakness, or had impaired cough (Table 1). We excluded studies of subjects with cystic fibrosis, as the Cystic Fibrosis Foundation recently published guidelines specifically related to airway clearance. ${ }^{9}$ Studies had to report on an agent of interest explicitly used to promote airway clearance and include a treatment group and an appropriate comparison group. Comparators included other pharmacologic airway clearance approaches, no airway clearance intervention, or placebo.

We also required that the studies addressed one of the outcomes related to the effects of the drug on mucus clearance outlined in Table 1. We included studies with any length of follow-up and in the hospital setting (ie, not home- or out-patient clinic-based).

\section{Study Selection}

Once we identified potential articles, we examined the abstracts to determine whether the studies met our criteria. Two reviewers separately evaluated each abstract for 
Table 1. Inclusion and Exclusion Criteria

\begin{tabular}{|c|c|}
\hline Category & Criteria \\
\hline Study population & $\begin{array}{l}\text { Hospitalized or postoperative subjects }>1 \mathrm{y} \text { of age without cystic fibrosis and receiving pharmacologic airway clearance } \\
\text { agents of interest } \\
\text { Subjects with neuromuscular disease or respiratory muscle weakness }>1 \mathrm{y} \text { of age without cystic fibrosis and receiving } \\
\text { pharmacologic airway clearance agents of interest } \\
\text { Subjects with impaired cough }>1 \mathrm{y} \text { of age without cystic fibrosis and receiving pharmacologic airway clearance agents } \\
\text { of interest }\end{array}$ \\
\hline Time period & 1970-2014 \\
\hline Publication languages & English only \\
\hline Admissible evidence & \\
\hline $\begin{array}{l}\text { Study design } \\
\text { Other criteria }\end{array}$ & 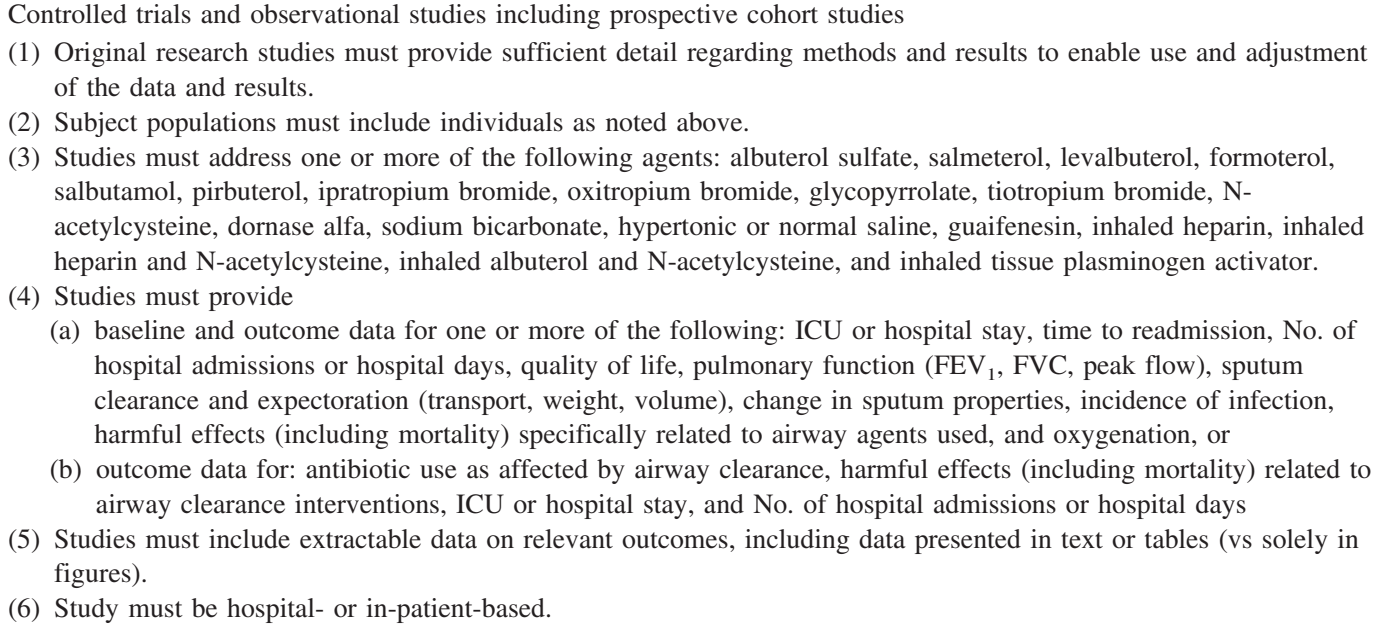 \\
\hline
\end{tabular}

inclusion or exclusion. If one reviewer concluded that the article could be eligible for the review based on the abstract, we retained it for full-text assessment. Two reviewers independently assessed the full text of each included study using a standardized form with questions stemming from our inclusion/exclusion criteria. Disagreements between reviewers were resolved by a senior reviewer. The group of abstract and full-text reviewers included expert clinicians and health services researchers, and we required that studies be excluded by at least one clinician and one methodologist.

\section{Data Extraction and Synthesis}

We extracted data on study design, population characteristics (including age, underlying conditions, and need for mechanical ventilation), intervention characteristics (including type and duration of intervention and concomitant therapies), and key outcomes into evidence tables. In addition to outcomes related to intervention effectiveness, we extracted all data available on harmful effects of airway clearance agents. Harmful effects encompass the full range of specific negative effects, including the narrower definition of adverse events. We determined that the differences among populations, interventions, controls, and outcome measures rendered meta-analysis inappropriate. Thus, analysis remained qualitative.

\section{Quality (Risk of Bias) Assessment of Individual Studies}

We assessed quality using separate tools as appropriate by study design. Tools included the Cochrane Risk of Bias Tool for randomized controlled trials (RCTs) and the Newcastle-Ottawa Scale for cohort studies. We rated the quality for key outcomes for which data were provided; if a study noted, for example, that a given outcome was not significantly different between groups but did not provide the relevant data, we did not rate quality for that outcome. Two reviewers independently assessed quality for each study, with final decisions made via discussion to reach consensus or by third-party adjudication by a senior methodologist as needed. We used the parameters outlined in Table 2 to translate quality ratings into final levels (good, fair, poor). We considered that good studies could not have any criteria rated as high risk of bias. For studies with unclear ratings, we considered the likelihood that a factor would bias a given outcome and the importance of the limitation and downgraded the final level as appropriate. 
Pharmacologic Agents for Airway Clearance

Table 2. Quality Rating Algorithm

\begin{tabular}{lccl}
\hline \hline $\begin{array}{l}\text { Low Risk of } \\
\text { Bias Criteria }\end{array}$ & $\begin{array}{c}\text { High Risk of } \\
\text { Bias Criteria }\end{array}$ & $\begin{array}{c}\text { Unclear Risk of } \\
\text { Bias Criteria }\end{array}$ & Quality Level \\
\hline 7 & 0 & 0 & Good \\
6 & 0,1 & 0,1 & Good or fair \\
5 & 0,1 & 1,2 & Good or fair \\
5 & 2 & 0 & Fair or poor \\
4 & $0-2$ & $0-3$ & Fair or poor \\
$0-3$ & $0-7$ & $0-7$ & Poor \\
$0-7$ & $3-7$ & $0-7$ & Poor \\
$0-7$ & $0-7$ & $4-7$ & Poor \\
\hline
\end{tabular}

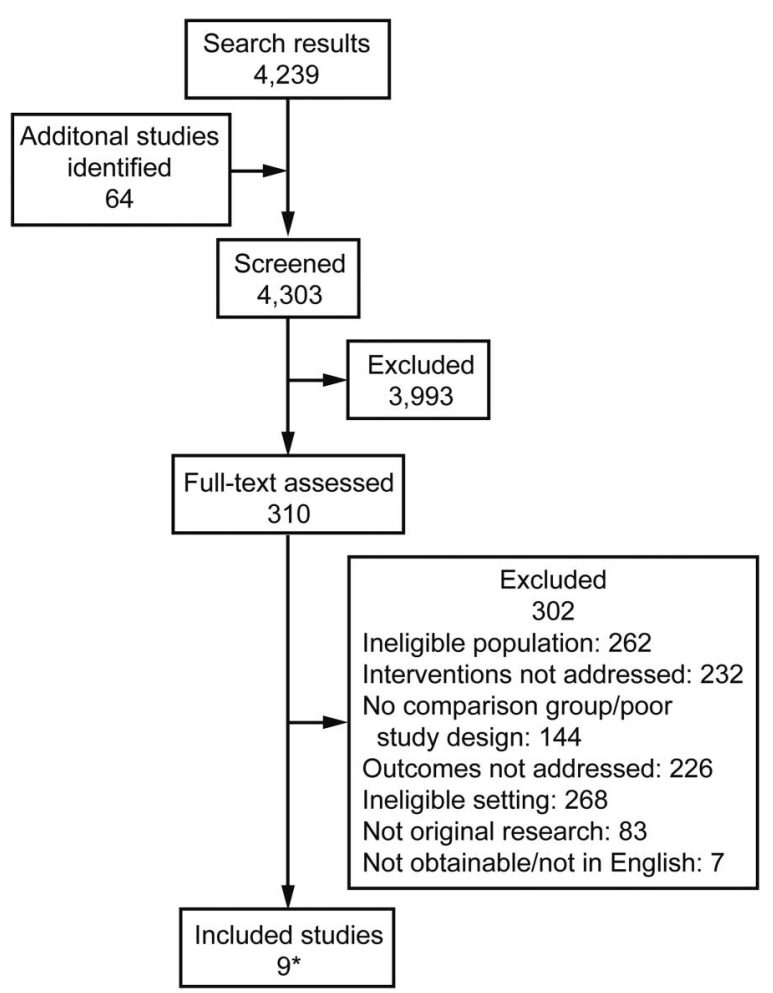

Fig. 1. Flow chart. Note that studies may fall under more than one exclusion category, for a total higher than actual. ${ }^{*}$ Reported in 8 papers.

Quality ratings for each outcome in the studies reviewed can be found in the online appendix.

\section{Results}

We reviewed 4,303 abstracts and 310 full-text papers and determined that 8 papers (comprising 9 unique studies) met inclusion criteria (Fig. 1). Excluded studies can be found in the supplemental materials at http://www.rcjournal. com. The 9 studies (reported in 8 publications) that met review criteria included 5 RCTs, 3 crossover RCTs, and one retrospective cohort study (Table 3 ). Studies were
Table 3. Overview of Included Studies

\begin{tabular}{|c|c|c|c|c|}
\hline Characteristic & $\mathrm{RCT}$ & $\begin{array}{l}\text { Crossover } \\
\text { RCT }\end{array}$ & Cohort & $\begin{array}{c}\text { Total } \\
\text { Literature* }\end{array}$ \\
\hline No. of studies & 5 & 3 & 1 & 9 \\
\hline \multicolumn{5}{|l|}{ Population } \\
\hline Adult & $5 \dagger$ & 3 & 0 & 8 \\
\hline Pediatric & 0 & 0 & 1 & 1 \\
\hline \multicolumn{5}{|l|}{ Underlying condition $\ddagger$} \\
\hline Asthma & 1 & 0 & 0 & 1 \\
\hline Bronchitis & 0 & 2 & 0 & 2 \\
\hline Burn injury & 0 & 0 & 1 & 1 \\
\hline COPD & 1 & 0 & 0 & 1 \\
\hline Postoperative & 3 & 0 & 0 & 3 \\
\hline \multicolumn{5}{|l|}{ Agents $§$} \\
\hline $\mathrm{N}$-acetylcysteine & 5 & 1 & 0 & 6 \\
\hline Albuterol & 0 & 1 & 0 & 1 \\
\hline $\begin{array}{l}\text { Heparin }+ \\
\quad \text { N-acetylcysteine }\end{array}$ & 0 & 0 & 1 & 1 \\
\hline Ipratropium bromide & 0 & 1 & 0 & 1 \\
\hline Saline & 2 & 1 & 0 & 3 \\
\hline \multicolumn{5}{|l|}{ Location } \\
\hline Asia & 1 & 0 & 0 & 1 \\
\hline Australia & 1 & 0 & 0 & 1 \\
\hline Europe & 1 & 1 & 0 & 2 \\
\hline US or Canada & 2 & 2 & 1 & 5 \\
\hline \multicolumn{5}{|c|}{$\begin{array}{l}\text { * One publication }{ }^{10} \text { included } 2 \text { studies in separate populations. } \\
\dagger \text { Age was not reported in } 2 \text { papers. }{ }^{10,14} \mathrm{We} \text { assumed that these were conducted in adult } \\
\text { populations. } \\
\ddagger \text { One study }{ }^{11} \text { included mechanically ventilated subjects with pulmonary or neurologic } \\
\text { conditions. } \\
\S \text { Studies could address more than one agent. } \\
\mid \text { One study } \\
\text { RCT }=\text { randomizesed controlled trial }\end{array}$} \\
\hline
\end{tabular}

small and together included a total of 379 subjects (mean of 42 participants per study). Five studies were conducted in $\leq 7 \mathrm{~d}$ (mean duration in these 5 studies of $5 \mathrm{~d}$ ). Two studies, one conducted in a skilled-nursing facility with mechanically ventilated subjects ${ }^{11}$ and one in a Veterans Affairs hospital, ${ }^{12}$ were conducted over 5 and 3 weeks, respectively. Duration of intervention was not clearly reported in 2 studies (reported in a single publication). ${ }^{10}$ Studies were conducted in the United States, ${ }^{10-13}$ the United Kingdom, ${ }^{14}$ Denmark, ${ }^{15}$ Iran, ${ }^{16}$ and Australia. ${ }^{17}$

The following sections summarize the results of studies meeting our criteria and categorized by agent (Table 4). Most studies were conducted in adults, and most assessed $\mathrm{N}$-acetylcysteine (6 studies), either alone or in combination with another agent. Individual studies referred to $\mathrm{N}$-acetylcysteine by various names, but we have used $\mathrm{N}$-acetylcysteine in our discussion of results for consistency. Adult populations included postoperative subjects (3 studies), subjects with chronic bronchitis (2 studies) or asthma (one study), subjects with COPD exacerbations (one study), and long-term mechanically ventilated subjects (one study). A single retrospective cohort study evaluated heparin plus 


\section{Pharmacologic Agents for Airway Clearance}

Table 4. Summary of Key Findings of Studies of Mucoactive Agents

\begin{tabular}{|c|c|c|c|}
\hline Reference (Study Design) & $\begin{array}{c}\text { Groups } \\
\text { ( } n \text { Subjects Enrolled/n Final Subjects) }\end{array}$ & $\begin{array}{c}\text { Population/Underlying } \\
\text { Condition, Mean Age } \pm \text { SD y }\end{array}$ & Key Findings \\
\hline \multicolumn{4}{|l|}{ Studies of N-acetylcysteine } \\
\hline Black et al ${ }^{17}$ (RCT) & $\begin{array}{l}\text { G1: Oral N-acetylcysteine }(25 / 25) \\
\text { G2: Placebo }(25 / 25)\end{array}$ & $\begin{array}{l}\text { Smokers with COPD } \\
\text { exacerbations } \\
\text { G1: } 73.6 \pm 7.8 \\
\text { G2: } 73.0 \pm 8.2\end{array}$ & $\begin{array}{l}\text { - Mean change in breathlessness score } \\
\text { of } 0.7 \text { points in } \mathrm{G} 1 \text { and } 0.8 \text { points in } \\
\mathrm{G} 2 \text {, mean change in } \mathrm{FEV}_{1} \text { of } 0.03 \mathrm{~L} \\
\text { in } \mathrm{G} 1 \text { and } 0.15 \mathrm{~L} \text { in } \mathrm{G} 2 \text {, mean } \\
\text { change in } \mathrm{S}_{\mathrm{pO}_{2}} \text { of } 1.2 \% \text { in } \mathrm{G} 1 \text { and } \\
1.8 \% \text { in } \mathrm{G} 2 \text {; no significant } \\
\text { differences in any measure } \\
\text { - No significant differences in stay } \\
\text { - Nausea reported in } 2 \text { subjects in } \mathrm{G} 2 \\
\text { and } 1 \text { subject in } \mathrm{G} 1\end{array}$ \\
\hline $\begin{array}{l}\text { Pulle et al }{ }^{12} \\
\quad(\text { crossover RCT) }\end{array}$ & $\begin{array}{l}\text { G1: Nebulized N-acetylcysteine } \\
\text { 10\% + isoproterenol } \\
\text { G2: Nebulized N-acetylcysteine } \\
\text { 0.05\% + isoproterenol } \\
\text { G3: Standard respiratory care } \\
\text { G1 + G2 + G3: } 20 / 20\end{array}$ & $\begin{array}{l}\text { Chronic or asthmatic bronchitis } \\
\mathbf{G 1}+\mathbf{G} \mathbf{2}+\mathbf{G 3}: 47-73\end{array}$ & $\begin{array}{l}\text { - } 17 \text { subjects with chronic bronchitis, } \\
\text { and nebulized isoproterenol included } \\
\text { in usual care }(0.05 \%) \\
\text { - Mean daily sputum volume not } \\
\text { significantly different among groups } \\
\text { - Decrease in sputum viscosity in } 10 \% \\
\text { N-acetylcysteine wk compared with } \\
\text { other wk }(P<.01) \\
\text { - No significant changes in pulmonary } \\
\text { function tests } \\
\text { - No instances of toxicity or other } \\
\text { adverse reactions }\end{array}$ \\
\hline $\begin{array}{l}\text { Aliyali et al }{ }^{16} \\
\quad(\mathrm{RCT})\end{array}$ & $\begin{array}{l}\text { G1: Oral N-acetylcysteine }+ \text { standard care } \\
(25 / 25) \\
\text { G2: Placebo }+ \text { standard care }(25 / 25)\end{array}$ & $\begin{array}{l}\text { Asthma exacerbations } \\
\text { G1: } 50 \pm 15.74 \\
\text { G2: } 47.8 \pm 12.06\end{array}$ & $\begin{array}{l}\text { No group differences in scores for } \\
\text { wheezing, cough, sleep, dyspnea, } \\
\text { sputum amount, morning peak } \\
\text { expiratory flow, and difficulty in } \\
\text { expectoration } \\
\text { No adverse events reported }\end{array}$ \\
\hline Jepsen et al15 (RCT) & $\begin{array}{l}\text { G1: Oral and intravenous N-acetylcysteine } \\
(62 / 30) \\
\text { G2: Placebo }(67 / 30)\end{array}$ & $\begin{array}{l}\text { Postoperative upper-laparotomy } \\
\text { subjects } \\
\text { G1: } 56.1 \text { (mean) } \\
\text { G2: } 50.7 \text { (mean) }\end{array}$ & $\begin{array}{l}\text { - No significant group differences in } \\
\text { pulmonary function tests, although } \\
\text { measures typically improved in both } \\
\text { groups over time } \\
\text { - No significant differences in } \\
\text { atelectasis or pulmonary infiltrates } \\
\text { (50\% of subjects in G1 and } 47 \% \text { in } \\
\text { G2) } \\
\text { - No significant differences in } \\
\text { analyses accounting for smoking } \\
\text { status, overweight, operation, or } \\
\text { preoperative vital capacity or FEV } \mathrm{F}_{1} \\
\text { reduction } \\
\text { - No adverse events in study period }\end{array}$ \\
\hline $\begin{array}{l}\text { Thomas et al }{ }^{10} \\
\text { (RCT) }\end{array}$ & $\begin{array}{l}\text { Experiment } 1 \\
\text { G1: Intratracheal N-acetyl-L-cysteine (20/20) } \\
\text { G2: Intratracheal saline (20/20) } \\
\text { Experiment } 2 \\
\text { G1: Intratracheal N-acetyl-L-cysteine }(20 / 20) \\
\text { G2: Intermittent positive-pressure delivered } \\
\quad \text { N-acetyl-L-cysteine }(20 / 20)\end{array}$ & $\begin{array}{l}\text { Postoperative abdominal } \\
\text { surgery subjects } \\
\text { Age: NR }\end{array}$ & $\begin{array}{l}\text { Experiment } 1 \\
\text { - } 4 \text { subjects in G1 and } 9 \text { in G2 } \\
\text { developed atelectasis } \\
\text { Experiment } 2 \\
\text { - } 4 \text { subjects in each group developed } \\
\text { atelectasis } \\
\text { - Harmful effects reported (not clear in } \\
\text { which set of subjects they occurred) } \\
\text { included subcutaneous bleeding } \\
(n=1) \text {, nausea ( } n=\mathrm{NR}) \text {, and } \\
\text { decreased appetite }(n=\mathrm{NR}) \text {. }\end{array}$ \\
\hline
\end{tabular}


Table 4. Continued

\begin{tabular}{|c|c|c|c|}
\hline Reference (Study Design) & $\begin{array}{c}\text { Groups } \\
\text { ( } n \text { Subjects Enrolled/n Final Subjects) }\end{array}$ & $\begin{array}{c}\text { Population/Underlying } \\
\text { Condition, Mean Age } \pm \text { SD y }\end{array}$ & Key Findings \\
\hline \multicolumn{4}{|l|}{ Studies of albuterol } \\
\hline $\begin{array}{l}\text { O'Riordan et al }{ }^{11} \\
\text { (crossover RCT) }\end{array}$ & $\begin{array}{l}\text { G1: Nebulized R-albuterol } \\
\text { G2: Nebulized racemic albuterol } \\
\text { G3: Nebulized saline } \\
\text { G1 + G2 + G3: } 17\end{array}$ & $\begin{array}{l}\text { Mechanically ventilated } \\
\text { subjects in skilled-nursing } \\
\text { facility } \\
\text { G1 + G2 + G3: } 72 \text { (range of } \\
\text { 35-93) }\end{array}$ & $\begin{array}{l}\text { - No significant group differences in } \\
\text { secretion volume at any collection } \\
\text { point } \\
\text { - Secretion volume greater on first } \\
\text { treatment day vs following } 4 \text { days in } \\
\text { all } 3 \text { groups } \\
\text { - No differences in mean electrolyte } \\
\text { concentrations and inflammatory } \\
\text { indices among groups } \\
\text { - No adverse events related to study } \\
\text { medications }\end{array}$ \\
\hline \multicolumn{4}{|l|}{$\begin{array}{l}\text { Studies of ipratropium } \\
\text { bromide }\end{array}$} \\
\hline $\begin{array}{l}\text { May and Palmer }{ }^{14} \\
\quad(\text { crossover RCT) }\end{array}$ & $\begin{array}{l}\text { G1: Nebulized ipratropium bromide } \\
\text { G2: Placebo } \\
\text { G1 + G2: } 12\end{array}$ & $\begin{array}{l}\text { Chronic bronchitis } \\
\text { Age: NR }\end{array}$ & $\begin{array}{l}\text { - No significant increase in mean } \\
\text { sputum viscosity or volume between } \\
\text { groups } \\
\text { - No adverse events reported }\end{array}$ \\
\hline \multicolumn{4}{|l|}{$\begin{array}{l}\text { Studies of heparin }+\mathrm{N}- \\
\text { acetylcysteine }\end{array}$} \\
\hline $\begin{array}{l}\text { Desai et al }{ }^{13} \\
\quad \text { (retrospective cohort) }\end{array}$ & $\begin{array}{l}\text { G1: Aerosolized heparin and N- } \\
\text { acetylcysteine }(47 / 47) \\
\text { G2: Standard inhalation injury care }(43 / 43)\end{array}$ & $\begin{array}{l}\text { Mechanically ventilated } \\
\text { children with burn and } \\
\text { inhalation injuries } \\
\text { G1: } 7.7 \pm 5 \\
\text { G2: } 8.2 \pm 6\end{array}$ & $\begin{array}{l}\text { - Significantly less need for re- } \\
\text { intubation in G1 vs G2 ( } 3 \text { vs } 12 \text {, } \\
P<.05) \\
\text { - Lower mortality in G1 vs G2 and } \\
\text { less atelectasis }(20 \text { vs } 30, P<.05) \\
\text { - Ventilator hours: } 1 \pm 93 \text { in } \mathrm{G} 1 \text { and } \\
187 \pm 79 \text { in G2 } \\
\text { - No adverse events reported }\end{array}$ \\
\hline $\begin{array}{l}\mathrm{RCT}=\text { randomized controlled trial } \\
\mathrm{G}=\text { group } \\
\mathrm{NR}=\text { not reported }\end{array}$ & & & \\
\hline
\end{tabular}

$\mathrm{N}$-acetylcysteine in mechanically ventilated, pediatric burn subjects.

\section{Summary of Results by Agent}

$\mathbf{N}$-acetylcysteine. Three small RCTs (one of good quality for all outcomes) evaluated $\mathrm{N}$-acetylcysteine in subjects with asthma, COPD, or bronchitis. The good-quality RCT was conducted in Australia and assessed the effects of $\mathrm{N}$-acetylcysteine on COPD exacerbations in long-term smokers who were $\geq 50$ y old. ${ }^{17}$ Investigators randomized subjects to either $600 \mathrm{mg}$ of oral $\mathrm{N}$-acetylcysteine twice daily in addition to usual care $(n=25$, mean age of $73.6 \pm 7.8 \mathrm{y})$ or placebo $(n=25$, mean age of $73 \pm 8.2 \mathrm{y})$ for $7 \mathrm{~d}$ or until discharge and measured the primary outcome of breathlessness (Likert scale from $1=$ extremely short of breath to $7=$ not at all short of breath) daily $2 \mathrm{~h}$ after the last dose of nebulized bronchodilator. Groups did not differ at baseline regarding age, smoking history, pulmonary function tests, use of bronchodilators and inhaled corticosteroids before admission, or breathlessness. Al- though the rate of change in breathlessness score, $\mathrm{FEV}_{1}$, and $\mathrm{S}_{\mathrm{pO}_{2}}$ was greater in the placebo group, changes were not significantly different between groups. The median hospital stay was $6.0 \mathrm{~d}$ in the $\mathrm{N}$-acetylcysteine group and $5.5 \mathrm{~d}$ in the placebo group ( $P=$ not reported). Two subjects in the placebo group and one in the $\mathrm{N}$-acetylcysteine group reported nausea. We considered this study as poor quality for reporting adverse effects.

A United States-based double-blind randomized crossover trial compared 2 concentrations of $\mathrm{N}$-acetylcysteine plus isoproterenol with standard respiratory care, which included isoproterenol, mucoactive drugs, expectorants, and humidification, in 20 males with chronic bronchitis $(n=17)$ or asthmatic bronchitis $(n=3) .{ }^{12}$ Subjects ranged in age from 47 to $73 \mathrm{y}$ and received standard therapy, including $0.05 \%$ isoproterenol delivered via an intermittent positive-pressure breathing device in the first study week. In the second and third weeks, subjects continued standard care and also received either $4 \mathrm{~mL}$ of $0.5 \% \mathrm{~N}$-acetylcysteine plus $0.05 \%$ isoproterenol in $0.9 \%$ saline 3 times daily or $4 \mathrm{~mL}$ of $10 \% \mathrm{~N}$-acetylcysteine plus $0.05 \%$ iso- 
proterenol 3 times daily in random order. The agents were delivered using a positive-pressure breathing device, and investigators compared the mean daily volume of sputum for each week, sputum viscosity, and pulmonary function. Mean daily sputum volume did not differ significantly among groups, but viscosity was significantly less in the $10 \% \mathrm{~N}$-acetylcysteine week than in the other weeks $(P<.01)$. Spirometry measures $\left(\mathrm{FEV}_{1}, \mathrm{FVC}\right.$, mid-expiratory flow, maximum mid-expiratory flow, maximum voluntary ventilation) were lowest in the control week and did not change significantly in the subsequent weeks. The investigators reported that no instances of toxicity or adverse reactions occurred. We considered this study as fair quality for the outcomes of sputum volume, viscosity, and pulmonary function and poor quality for adverse effects.

In one single-blind placebo-controlled RCT conducted in Iran, 25 subjects with asthma exacerbations received usual care plus $600 \mathrm{mg}$ of oral $\mathrm{N}$-acetylcysteine twice daily (mean age of $50 \pm 15.7 \mathrm{y}$, mean asthma duration of $8.1 \pm 7.1 \mathrm{y}$ ). ${ }^{16}$ The 25 subjects in the control group (mean age of $47.8 \pm 12.1 \mathrm{y}$, mean asthma duration of $8.0 \pm 8.5 \mathrm{y}$ ) received usual asthma care. All subjects in both groups received inhaled corticosteroids, systemic corticosteroids, inhaled $\beta_{2}$ agonists, and macrolide antibiotics $(n=15$ in the $\mathrm{N}$-acetylcysteine group and 12 in the control group) during the study period. Groups did not differ significantly at baseline regarding demographic measures or measures of severity of dyspnea, wheezing, cough, sputum amount, difficulty in expectoration, or morning peak expiratory flow. At day 5, symptom severity in both groups had improved from baseline, but between-group differences were not significant. The study did not report adverse events. We rated this study as poor quality for the outcomes of dyspnea, wheezing, cough, sputum amount, ease of expectoration, and sleep quality. The study was of fair quality for the outcome of peak expiratory flow.

Three studies included postoperative subjects. A double-blind RCT conducted in Denmark compared N-acetylcysteine $(n=64)$ with placebo $(n=67)$ in subjects undergoing upper laparotomy. ${ }^{15} \mathrm{We}$ rated this study as poor quality for all outcomes, including adverse effects. Surgical procedures included cholecystectomy $(55 \%$ in the $\mathrm{N}$-acetylcysteine group and $61 \%$ in the placebo group) and biliary or gastric surgeries (45\% in the $\mathrm{N}$-acetylcysteine group and $39 \%$ in the placebo group). The overall mean age of subjects was $53.3 \mathrm{y}$ (56.1 y in the $\mathrm{N}$-acetylcysteine group and $50.7 \mathrm{y}$ in the placebo group; significance testing not reported), and groups did not differ significantly in terms of sex, number of smokers, percent overweight, and major versus minor surgeries. Subjects in the $\mathrm{N}$-acetylcysteine group received a total of $1,200 \mathrm{mg}$ of N-acetylcysteine orally the day before surgery and $200 \mathrm{mg}$ intravenously or orally 3 times/d for $6 \mathrm{~d}$ or until discharge. Investigators assessed pulmonary function preoperatively and on postoperative days 1,3 , and 5 and used chest radiographs to evaluate atelectasis on postoperative days 2 and 4 . By day 6 , only 60 subjects remained in the study (30 in each group). At 6-d post-surgery, the between-group difference in mean actual and preoperative alveolar-arterial $\mathrm{O}_{2}$ difference was not significant, nor was it significantly different between groups on any day. Vital capacity and $\mathrm{FEV}_{1}$ improved in both groups by day 6 (N-acetylcysteine median of $17.9 \%$ vs $23.8 \%$ and $21.4 \%$ vs $26.4 \%$ in the placebo group, respectively), but between-group differences were not significant. In covariate analyses, no pulmonary function outcomes differed by smoking or overweight status, type of surgery, or reduction in preoperative pulmonary values. Fifty percent of the $\mathrm{N}$-acetylcysteine group and $47 \%$ of the placebo group had atelectasis on day 4 , and $3 \%$ overall had pneumonic infiltrations; differences in frequency of atelectasis or infiltrations between groups were not significant ( $P=.18$ for atelectasis). Investigators reported that no adverse effects were recorded in the study period.

One study reported noncomparative data and outcomes of 2 unblinded randomized trials of $\mathrm{N}$-acetylcysteine to minimize atelectasis in 2 different populations of postoperative subjects ${ }^{10}$; we considered it to be poor quality for all outcomes. The study did not report subject characteristics; however, one trial compared $\mathrm{N}$-acetylcysteine $(10 \%$ solution, $2 \mathrm{~mL}$ every $2 \mathrm{~h}$ for 10 doses after anesthesia recovery) and physiologic saline ( $2 \mathrm{~mL}$ every $2 \mathrm{~h}$ ) in 40 abdominal surgery subjects (20 in each group), and another trial compared intratracheally instilled N-acetylcysteine with nebulized $\mathrm{N}$-acetylcysteine delivered via an intermittent positive-pressure breathing device in another 40 abdominal surgery subjects. In both trials, subjects received normal postoperative nursing care, and atelectasis was assessed via chest radiographs. In the first trial, 9 of 20 subjects in the saline group compared with 2 of 20 in the $\mathrm{N}$-acetylcysteine group developed atelectasis. The incidence of atelectasis did not differ between groups receiving either the intratracheally instilled agent or the agent delivered via the positive-pressure breathing device (4 of 20 subjects with atelectasis in both groups). The study also reported data on the number of subjects by surgical type who received or did not receive $\mathrm{N}$-acetylcysteine and who developed atelectasis, although it is not clear if these subjects included the abdominal surgery subjects described in the trials. Although the number of subjects receiving each type of surgery varied, 33 of 124 subjects who did not receive the agent developed atelectasis, with the highest rates after gynecologic surgeries (60\%, 3 of 5 subjects), colonic surgeries (38\%, 3 of 8 subjects), and lung pneumonectomy (33\%, 2 of 6 subjects). Fourteen of 97 subjects who received $\mathrm{N}$-acetylcysteine developed atelectasis, with the highest rates after gastric surgeries (33\%, 3 of 9 subjects), thoracic surgeries (23\%, 3 of 13 subjects), and bil- 
iary tract surgeries (21\%, 4 of 19 subjects). The study notes that an unstated number of subjects complained of nausea and decreased appetite related to $\mathrm{N}$-acetylcysteine, and one subject had serious bleeding at the puncture site for intratracheal instillation.

Albuterol. One placebo-controlled randomized crossover trial conducted in the United States included 14 mechanically ventilated subjects in a long-term care facility (median age of $72 \mathrm{y}$, range of 35-93 y; median intubation duration of 21 months, range of 4-108 months). ${ }^{11}$ Six subjects had COPD, and one had idiopathic pulmonary fibrosis. Neurologic conditions included amyotrophic lateral sclerosis $(n=2)$, neuropathy $(n=2)$, myopathy $(n=2)$, and encephalopathy $(n=1)$. Subjects underwent a 2-week washout phase in which all aerosolized bronchodilators were discontinued. Subjects receiving inhaled corticosteroids ( $n=1)$, systemic corticosteroids $(n=2)$, and $\beta$-sympathomimetic antagonists $(n=1)$ continued those medications. Investigators measured secretion volume daily for 1 week following the washout period to establish control volumes. Following this week, subjects received, in random order, $5 \mathrm{~d}$ of an R-enantiomer formulation (R-albuterol, $1.25 \mathrm{mg} / 3 \mathrm{~mL} 3$ times/d), racemic albuterol $(2.5 \mathrm{mg} / 3 \mathrm{~mL}$ 3 times/d), or normal saline ( $3 \mathrm{~mL} 3$ times/d). Treatments were nebulized and were given each weekday, with each weekend serving as a washout period between treatments.

All subjects completed the control period, 12 completed the saline phase, 14 completed the racemic albuterol phase, and 13 completed the R-albuterol phase. Investigators collected secretions from suctioning (provided at medication administration and as needed) and cough and mucus clearance for $4 \mathrm{~h}$ after each treatment and totaled all values for a 5-d aggregate volume at 1 and $4 \mathrm{~h}$ of collection. Differences in aggregate 4-h sputum volume over $5 \mathrm{~d}$ were not significantly different among groups (mean \pm SEM in the control period of $31 \pm 8.9 \mathrm{~mL}$, saline $=25.1 \pm 5.5 \mathrm{~mL}$, racemic albuterol $=24.9 \pm 4.9 \mathrm{~mL}, \mathrm{R}$-albuterol $=26.9 \pm 6.8 \mathrm{~mL}$ ), nor were daily 4 -h aggregate differences or differences at $1 \mathrm{~h}$ of collection. For all 3 treatments, the volume on the first day of collection after starting a treatment was greater at the first-hour measurement than at $4 \mathrm{~h}(P=.01)$. Neither mean electrolyte concentrations nor mean inflammatory indexes differed significantly among treatment groups. The study reported that there were no adverse events related to the study drugs. We rated the study as fair quality for the outcomes of sputum volume, electrolyte concentrations, and inflammatory indexes and poor quality for harmful effects.

Ipratropium Bromide. In a poor-quality randomized crossover trial conducted in Scotland, 12 in-patients with chronic bronchitis received $40 \mu \mathrm{g}$ of aerosolized ipratropium bromide or a placebo containing a propellant only in random order. ${ }^{14}$ Subjects (no baseline characteristics provided) received each treatment for $2 \mathrm{~d}$, and investigators measured the volume of collected sputum after $24 \mathrm{~h}$ and sputum viscosity. The mean change in viscosity in the ipratropium bromide group was $91.6 \pm 44.3$ centipoise, and that in the placebo group was $73.0 \pm 29.6$ centipoise. The mean change in sputum volume at $24 \mathrm{~h}$ was $33.3 \pm 19.7 \mathrm{~mL}$ in the ipratropium bromide group and $34.0 \pm 20.4 \mathrm{~mL}$ in the placebo group. Although the study did not report baseline values, the investigators noted that increases in volume or viscosity were not significant. The study also did not report adverse events.

Heparin and $\mathrm{N}$-acetylcysteine. One fair-quality cohort study compared aerosolized heparin and $\mathrm{N}$-acetylcysteine in pediatric burn subjects with inhalation injury requiring mechanical ventilation with standard inhalation injury care. ${ }^{13}$ Forty-seven children admitted to one United States hospital received standard care plus 5,000 units of aerosolized heparin alternating with $3 \mathrm{~mL}$ of a $20 \%$ solution of $\mathrm{N}$-acetylcysteine every $2 \mathrm{~h}$ for the first $7 \mathrm{~d}$ after injury (mean age of $7.7 \pm 5 \mathrm{y}$ ). Children in the control group $(n=43$, mean age of $8.2 \pm 6 \mathrm{y})$ received standard inhalation injury care (ventilatory support, humidified oxygen, chest physical therapy, suctioning, bronchodilation, ambulation). Children did not differ significantly in age, percent of total body surface burned, or hospital stay. Significantly fewer children in the heparin and $\mathrm{N}$-acetylcysteine group required re-intubation for pulmonary failure ( $3 / 47$ vs $12 /$ 43 ), had atelectasis (20/47 vs $30 / 43$ ), or died ( $2 / 47$ vs $8 / 43$ ) compared with the control group (all $P$ values $<.05$ ). The treatment group required fewer ventilator hours than the control group (mean of $81 \pm 93$ vs $187 \pm 79 \mathrm{~h}$, calculated $P<.001$, unpaired $t$ test). The study did not report adverse events.

\section{Discussion}

Nine small, mostly poor-quality studies met our review criteria. Studies most frequently addressed sputum volume and pulmonary function measures with no significant between-group differences for any agent on any measure of these outcomes (Table 5). Subject populations varied across studies and included subjects with COPD, bronchitis, asthma, and burn injuries, as well as mechanically ventilated and postoperative subjects. Comparators and outcome measures also varied across studies. Three RCTs used a placebo comparator, and 4 were crossover studies. Studies typically measured sputum volume or viscosity using different techniques or measured pulmonary function $\left(\mathrm{FEV}_{1}\right)$. Subjects generally also received standard respiratory care, which may have included other pharmacologic agents, suctioning, or chest physical therapy. Sources of heterogeneity across studies meant that meta-analysis was not appropriate or feasible. The overall body of evi- 
Table 5. Summary of Between Group Differences in Final Outcomes

\begin{tabular}{|c|c|c|c|c|c|c|c|}
\hline Reference & Groups & Population & $\begin{array}{c}\text { Sputum } \\
\text { Volume/ } \\
\text { Weight }\end{array}$ & Viscosity & $\begin{array}{l}\text { Pulmonary } \\
\text { Function }\end{array}$ & $\mathrm{S}_{\mathrm{pO}_{2}}$ & Atelectasis \\
\hline Aliyali et $\mathrm{al}^{16}$ & $\mathrm{~N}$-acetylcysteine and placebo & Asthma & * & NR & $*$ & NR & NR \\
\hline Black et al ${ }^{17}$ & $\mathrm{~N}$-acetylcysteine and placebo & COPD & NR & NR & $*$ & $*$ & NR \\
\hline Jepsen $^{15}$ & $\mathrm{~N}$-acetylcysteine and placebo & Postoperative & NR & NR & $*$ & NR & $*$ \\
\hline Pulle et al ${ }^{12}$ & $\begin{array}{l}\mathrm{N} \text {-acetylcysteine }(0.5 \% \text { or } 10 \%) \\
\quad+\text { isoproterenol and usual care }\end{array}$ & $\begin{array}{l}\text { Chronic asthma or } \\
\text { bronchitis }\end{array}$ & $*$ & $\begin{array}{l}10 \% \mathrm{~N}- \\
\text { acetylcysteine } \dagger\end{array}$ & $*$ & NR & NR \\
\hline $\begin{array}{l}\text { O'Riordan } \\
\text { et } \mathrm{al}^{11}\end{array}$ & $\begin{array}{l}\text { R-albuterol, racemic albuterol, } \\
\text { and saline }\end{array}$ & $\begin{array}{l}\text { Mechanically ventilated, } \\
\text { long-term care }\end{array}$ & $*$ & NR & NR & NR & NR \\
\hline Desai et al ${ }^{13}$ & $\begin{array}{l}\text { Heparin }+\mathrm{N} \text {-acetylcysteine and } \\
\text { usual care }\end{array}$ & Inhalation injury & NR & NR & NR & NR & $\begin{array}{l}\text { Heparin }+\mathrm{N}- \\
\text { acetylcysteine } \dagger\end{array}$ \\
\hline $\begin{array}{l}\text { May and } \\
\text { Palmer }{ }^{14}\end{array}$ & Ipratropium bromide and placebo & Bronchitis & $*$ & $*$ & NR & NR & NR \\
\hline Thomas et $\mathrm{al}^{10} \ddagger$ & $\begin{array}{l}\text { Intratracheal N-acetylcysteine and } \\
\text { IPPB N-acetylcysteine }\end{array}$ & Postoperative & NR & $*$ & NR & NR & $*$ \\
\hline \multicolumn{8}{|c|}{$\begin{array}{l}\text { NR }=\text { not reported } \\
\text { IPPB = intermittent positive-pressure breathing } \\
\text { * There were no significant differences between groups. } \\
\dagger \text { Decrease was significantly different between groups. } \\
\ddagger \text { The second study in this publication did not report potential significance of differences in outcomes. }\end{array}$} \\
\hline
\end{tabular}

dence for any agent on outcomes related to airway clearance is methodologically weak and precludes any conclusions on the effectiveness or harmful effects of the agents studied. To supplement the limited harmful effect data included in the studies addressed in the review, we have included an analysis of adverse events reported in product labeling for each agent in supplemental materials available at http://www.rcjournal.com.

\section{Summary of Results by Outcome}

Sputum Volume or Weight and Sputum Viscosity. Four studies assessed sputum volume or weight with mixed results. One crossover study of varied concentrations of $\mathrm{N}$-acetylcysteine plus isoproterenol reported no group differences in sputum volume, ${ }^{12}$ as did an RCT assessing $\mathrm{N}$-acetylcysteine versus placebo in subjects with asthma exacerbations. ${ }^{16}$ Crossover RCTs of ipratropium bromide and albuterol reported no group differences in secretion volume. ${ }^{11,14}$ One crossover study of $\mathrm{N}$-acetylcysteine reported decreases in sputum viscosity after treatment. ${ }^{12}$ One crossover trial of ipratropium bromide reported no increase in viscosity after treatment. ${ }^{14}$

Expectoration. One study of $\mathrm{N}$-acetylcysteine reported no differences in ease of expectoration between the $\mathrm{N}$-acetylcysteine and placebo groups. ${ }^{16}$

Pulmonary Function. Four studies reported no differences in pulmonary function measures associated with treatment: one crossover RCT of $\mathrm{N}$-acetylcysteine and isoproterenol $^{12}$ and 3 RCTs comparing $\mathrm{N}$-acetylcysteine and placebo. ${ }^{15-17}$ Pulmonary measures included peak flow, $\mathrm{FEV}_{1}$, dyspnea, and vital capacity.

Atelectasis. Three studies reported on incidence of atelectasis. In one RCT of aerosolized heparin and N-acetylcysteine compared with placebo, fewer children in the treatment group developed atelectasis compared with the placebo group. ${ }^{13}$ Two studies of $\mathrm{N}$-acetylcysteine reported no group differences in atelectasis. ${ }^{10,15}$ One of these studies ${ }^{10}$ reported 2 separate experiments and found no differences in development of atelectasis in one experiment and did not assess significance in the second, although 9 of 20 subjects in the saline group and 2 of 20 in the N-acetylcysteine group developed atelectasis.

Other Outcomes and Harmful Effects of Treatments. Other outcomes reported included $\mathrm{S}_{\mathrm{pO}_{2}}$ (no group differences in one $\mathrm{RCT}^{17}$ ); hospital stay (no group differences in one RCT of N-acetylcysteine ${ }^{17}$ ); cough, wheezing, and sleep (no significant differences between groups in one $\mathrm{RCT}^{16}$ ); mortality, ventilation hours, and re-intubation (significant differences in favor of the heparin and $\mathrm{N}$-acetylcysteine group vs usual care $^{13}$ ); and electrolyte concentration and inflammation indexes (no differences in a crossover trial of albuterol ${ }^{11}$ ). Harmful effects of agents were not consistently reported. Two studies of N-acetylcysteine reported nausea (one paper reported 2 experiments and did not clearly identify in which experiment adverse effects occurred), ${ }^{10,17} 3$ studies reported that there were no adverse events, ${ }^{11,12,15}$ and 3 studies did not address adverse effects at all. ${ }^{13,14,16}$ 


\section{Methodological Considerations and Limitations}

As noted, very few comparative studies addressed mucoactive agents, and we rated only one as good quality for any outcome. Studies typically did not adequately characterize populations, interventions, or methods. Additionally, studies included few subjects, and a number of studies used a less rigorous design (crossover). Subjects also received additional airway clearance care, which was often not well described, and disentangling potential effects was not possible. Studies were typically conducted over 5 y ago (one in 2010, one in 2006, one in 2004, one in the 1990s, one in the 1980s, and 4 in the 1960s or 1970s) and may not reflect current techniques and best practices in respiratory care. Few studies explicitly addressed adverse effects of agents used.

\section{Future Research}

Given the dearth of good-quality research, additional studies of all agents for mucus clearance are needed. The limited number of comparative studies and their limited quality prohibit drawing conclusions from the current body of literature. Future studies should adequately characterize populations, including other interventions that were delivered concurrently with a mucoactive agent, to promote combining smaller samples and a clear understanding of the potential effects of the study drug. Future research of a new agent should be conducted in adequately powered RCTs using either a placebo comparison or a current bestpractice agent as a comparator. Additionally, future research should clearly describe methods for randomization and for adverse effect assessment, study duration, and any follow-up beyond the immediate study period.

\section{Conclusions}

Few comparative studies addressed mucoactive agents that promote airway clearance in hospitalized subjects. Those that did were of limited quality and do not permit conclusions about effectiveness. Other reviews of mucoactive drugs have noted a similar lack of evidence or limited evidence to support the use of these drugs. ${ }^{18-20}$ Only 2 studies reported significant group differences in the outcomes of sputum viscosity and atelectasis. Changes in sputum volume, pulmonary function, and $\mathrm{S}_{\mathrm{pO}_{2}}$ did not differ significantly between groups in studies of any agent.

\section{ACKNOWLEDGMENTS}

We gratefully acknowledge the contributions of the members of the AARC Airway Clearance Clinical Practice Guideline Committee. Their insight into scoping the literature and reviewing studies was invaluable. The committee includes Richard D Branson MSc RRT FAARC, Gail S Drescher MA RRT, Carl F Haas MLS RRT-ACCS FAARC, Dean R
Hess PhD RRT FAARC, Ray Masferrer RRT FAARC, Catherine A O'Malley RRT-NPS, Bruce K Rubin MD MEngr MBA FAARC, Shawna L Strickland PhD RRT-NPS ACCS AE-C FAARC, and Teresa A Volsko MHHS RRT FAARC.

\section{REFERENCES}

1. Rogers DF. Mucoactive agents for airway mucus hypersecretory diseases. Respir Care 52(9):1176-1193, 2007; discussion 1193-1177.

2. Balsamo R, Lanata L, Egan CG. Mucoactive drugs. Eur Respir Rev 2010;19(116):127-133.

3. Bhowmik A, Chahal K, Austin G, Chakravorty I. Improving mucociliary clearance in chronic obstructive pulmonary disease. Respir Med 2009;103(4):496-502.

4. Sadowska AM, Verbraecken J, Darquennes K, De Backer WA. Role of $\mathrm{N}$-acetylcysteine in the management of COPD. Int J Chron Obstruct Pulmon Dis 2006;1(4):425-434.

5. Rubin BK. The pharmacologic approach to airway clearance: mucoactive agents. Paediatr Respir Rev 2006;7(Suppl 1):S215-S219.

6. Rubin BK. Mucolytics, expectorants, and mucokinetic medications. Respir Care 2007;52(7):859-865.

7. Ramos FL, Krahnke JS, Kim V. Clinical issues of mucus accumulation in COPD. Int J Chron Obstruct Pulmon Dis 2014;9:139-150.

8. Andrews J, Sathe NA, Krishnaswami S, McPheeters ML. Nonpharmacologic airway clearance techniques in hospitalized patients: a systematic review. Respir Care 2013;58(12):2160-2186.

9. Flume PA, Robinson KA, O’Sullivan BP, Finder JD, Vender RL, Willey-Courand DB, et al. Cystic fibrosis pulmonary guidelines: airway clearance therapies. Respir Care 2009;54(4):522-537.

10. Thomas PA, Lynch RE, Merrigan EH. Prevention of postoperative pulmonary atelectasis: review of 215 cases and evaluation of acetylcysteine. Am Surg 1966;32(5):301-307.

11. O'Riordan TG, Mao W, Palmer LB, Chen JJ. Assessing the effects of racemic and single-enantiomer albuterol on airway secretions in long-term intubated patients. Chest 2006;129(1):124-132.

12. Pulle DF, Glass P, Dulfano MJ. A controlled study of the safety and efficacy of acetylcysteine-isoproterenol combination. Curr Ther Res Clin Exp 1970;12(8):485-492.

13. Desai MH, Mlcak R, Richardson J, Nichols R, Herndon DN. Reduction in mortality in pediatric patients with inhalation injury with aerosolized heparin/N-acetylcystine therapy. J Burn Care Rehabil 1998;19(3):210-212.

14. May CS, Palmer KN. Effect of aerosol ipratropium bromide $(\mathrm{SCH}$ 1000) on sputum viscosity and volume in chronic bronchitis. Br J Clin Pharmacol 1977;4(4):491-492.

15. Jepsen S, Klaerke A, Nielsen PH, Nielsen ST, Simonsen O. Systemic administration of $\mathrm{N}$-acetylcysteine has no effect on postoperative lung function following elective upper laparotomy in lung healthy patients. Acta Anaesthesiol Scand 1989;33(3):219-222.

16. Aliyali M, Poorhasan Amiri A, Sharifpoor A, Zalli F. Effects of $\mathrm{N}$-acetylcysteine on asthma exacerbation. Iran J Allergy Asthma Immunol 2010;9(2):103-109.

17. Black PN, Morgan-Day A, McMillan TE, Poole PJ, Young RP. Randomised, controlled trial of $\mathrm{N}$-acetylcysteine for treatment of acute exacerbations of chronic obstructive pulmonary disease [ISRCTN21676344]. BMC Pulmon Med 2004;4:13.

18. Wilkinson M, Sugumar K, Milan SJ, Hart A, Crockett A, Crossingham I. Mucolytics for bronchiectasis. Cochrane Database Syst Rev 2014;5:CD001289.

19. Poole P, Black PN, Cates CJ. Mucolytic agents for chronic bronchitis or chronic obstructive pulmonary disease. Cochrane Database Syst Rev 2012;8:CD001287.

20. De Coster DA, Jones M, Thakrar N. Beclometasone for chronic obstructive pulmonary disease. Cochrane Database Syst Rev 2013; 10:CD009769. 